\title{
Wind power: the economic impact of intermittency
}

\author{
G. Cornelis van Kooten
}

Received: 24 June 2009 / Accepted: 11 November 2009 / Published online: 21 November 2009

(C) The Author(s) 2009. This article is published with open access at Springerlink.com

\begin{abstract}
Wind is the fastest growing renewable energy source for generating electricity, but economic research lags behind. In this study, therefore, we examine the economics of integrating large-scale wind energy into an existing electrical grid. Using a simple grid management model to investigate the impact of various levels of wind penetration on grid management costs, we show that costs of reducing $\mathrm{CO}_{2}$ emissions by relying more on wind power depend on the generation mix of the existing electrical grid and the degree of wind penetration, with costs ranging from $\$ 44$ to well over $\$ 1000$ per tonne of $\mathrm{CO}_{2}$ reduced. Costs are lowest if wind displaces large amounts of fossil fuel production and there is some hydroelectric power to act as a buffer. Hydro capacity has the ability to store wind generated power for use at more opportune times. If wind does nothing more than replace hydro or nuclear power, however, the environmental benefits (reduced $\mathrm{CO}_{2}$ emissions) of investing in wind power are small.
\end{abstract}

Keywords Wind power - Carbon costs · Electrical grids · Mathematical programming

JEL Classification Q54 - Q41 · C61

\section{Introduction}

Because of their ubiquity, fossil fuels have become the backbone of industrial economies, while the electricity supply infrastructure is their spinal cord. Burning of fossil fuels emits gases that contribute to global climate change and local pollution, while dependence on oil and gas raises concerns about supply security. For these

G.C. van Kooten $(\bowtie)$

University of Victoria, P.O. Box 1700, Stn CSC, Victoria, BC V8W 2Y2, Canada

e-mail: kooten@uvic.ca 
reasons, countries seek renewable sources of energy for generating electricity. These include wind, solar and tidal forms that suffer from intermittency in supply which cannot easily be overcome through storage. Yet, wind is now the fastest growing renewable energy source for generating electricity (van Kooten and Timilsina 2009).

In this study, we focus on the potential economic concerns of integrating largescale wind energy into an existing electrical grid, emphasizing in particular the costs associated with intermittency. Two approaches to estimating the indirect costs of wind variability can be identified. First, some researchers have focused on the costs of additional system reserves required to cover the increased variability of wind (Gross et al. 2003, 2006; Piwko et al. 2005). These reserves constitute short-term balancing (regulating) reserves that are available immediately (spinning reserves) or within some 10 minutes (gas turbines), and long-term contingency reserves that can replace power from large unit outages. When wind generating capacity is installed on a large scale, greater system balancing reserves are required than would be the case if an equivalent amount of thermal or hydro capacity were installed, even after adjusting for the lower capacity factors associated with wind. Contingency reserves are unaffected because, as we demonstrate in this paper, wind cannot be used to meet base load demand, despite arguments that this is possible if only wind farms are spread over a large enough geographic area.

The second approach focuses directly on management aspects-how the generators adjust (and thereby the implications on reserves) and the costs of retaining system balance (Lund 2005). Most system operators are required by lawmakers to treat wind power as non-dispatchable or 'must run'; that is, wind generated power must be accepted into the grid whenever it is available and cannot be curtailed. As a result, extant generators must be ready to dispatch power to the grid in the event of a decline in wind availability. Fluctuations in wind result in increased ramping-up and ramping-down of base-load generators, failure of slow-ramping facilities to follow variations in load, and more frequent starts and stops of peak-load (open-cycle) gas plants, thereby leading to increased operating and maintenance (O\&M) costs. While this problem could be mitigated by storage, no viable large-scale storage systems are currently available. ${ }^{1}$ Because of the storage problem, wind power is used most effectively in electrical grids that have large hydropower capacity. In that case, water can be stored in reservoirs by withholding hydroelectricity from the grid, releasing water and generating electricity when there is no wind power.

The second approach is employed in this study. It is based on the notion that a suitable constrained optimization model of an electrical grid that assumes rational expectations (load and wind power availability are known beforehand) should project costs that are equal to or lower than those based on rule-of-thumb requirements regarding additional reserves (Gross et al. 2006, 2007). The only difference is that a

\footnotetext{
${ }^{1}$ Excess power can be used to produce hydrogen for fuel cells, to compress air that is released to generate electricity when needed or to pump water into a reservoir, or stored in very large batteries. While each of these storage methods has promise, none is currently in widespread use or available on a large scale at reasonable cost. Greenblatt et al. (2007), for example, find fast-responding (open-cycle) natural gas as a supplement to variable wind power to be superior to underground compressed air storage, except at very high prices for natural gas.
} 
grid optimization model takes explicit account of the need to balance output from existing generators on the grid (see Maddaloni et al. 2008). ${ }^{2}$

We focus on existing grids because wind generating capacity can be installed quite quickly (often within a year); in the United States, for example, installed wind capacity increased at an annual rate of $30.7 \%$ since 2000 . It is also very difficult to shut down base-load power plants simply because wind is now available-wind power is too unreliable. Further, many public and private owners of coal plants have only recently invested in new technologies to meet ever-stringent environmental guidelines, and this has increased the life of many facilities by several decades. Indeed, in some jurisdictions where nuclear power plants are being decommissioned, reliance on coal plants might actually increase. In jurisdictions where coal plants are scheduled to come off line, they are often replaced by gas plants because decision-makers have been reluctant to build new nuclear or coal plants as replacements, gas emits less $\mathrm{CO}_{2}$ per $\mathrm{kWh}$ than coal, and gas plants can be built cheaply and quickly. ${ }^{3}$ Therefore, it makes sense to examine how the economics of wind power is impacted when wind is introduced at various levels of penetration into grids with different generating mixes. Questions related to the optimal removal of coal generating resources and the determination of an optimal generating mix are left to future research.

We begin in the next section by examining the issue of integrating wind power into electrical grids in more detail, and developing a model for estimating the potential costs of integrating varying amounts of wind into grids with differing generation mixes. The results are provided in Sect. 3. We find that a grid dominated by fossil fuel generating capacity but with adequate hydroelectric facilities that can store wind generated power at crucial times is optimally suited for large wind farms. Somewhat surprisingly, however, the costs of reducing $\mathrm{CO}_{2}$ emissions are higher than socially desirable in the cases we examine. Some concluding observations follow in Sect. 4.

\section{Integrating wind power into electrical grids}

Consider how conventional generation capacity can be replaced by wind capacity while maintaining system reliability for a large, relatively isolated electrical grid (Love et al. 2003; Pitt et al. 2005). To do so, we employ hourly load data from the ERCOT (Texas) system for 2007, and wind data from sites located in western Canada. ${ }^{4}$

\footnotetext{
${ }^{2}$ The first approach for calculating reserves relies on known information about wind variability as much as the second approach.

${ }^{3}$ The problem was recently highlighted in The Economist (8 August 2009, pp. 49-50). The UK delayed building new capacity except for wind-it now has the largest off-shore wind generating capacity in the world $(600 \mathrm{MW})$. Because its nuclear power plants are simply too old to be rejuvenated, the UK will either have to invest heavily in gas or keep its coal plants running, thereby failing to meet emission reduction targets. Ontario in Canada has a similar problem, but may be able to substitute some coal with biomass in its base-load plants and/or rely more on imported power.

${ }^{4}$ ERCOT load data were available at: http://www.ercot.com/gridinfo/load/load_hist/ (viewed 12 June 2008). Wind speed data are from BC Hydro and were available at: http://www.bchydro.com/environment/ greenpower/greenpower1764.html (viewed 27 January 2007). Alberta wind farm output data were available from the Alberta Electric System Operator (http://www.aeso.ca viewed January 2007). However, data are no longer available at these sites. Thus, all the load and wind information used in this study are available at: http://web.uvic.ca/ kooten/documents/LSRS2009WindData.xls.
} 
The ERCOT load data are standardized to a peak load of 2,500 MW (the ERCOT peak demand is $62,101 \mathrm{MW}) .{ }^{5}$ Actual wind power output data are available on an hourly basis for sites in Alberta, while hourly wind speed data are available for sites in north-eastern British Columbia. The two regions for wind data are chosen because they are both located immediately east of the Rocky Mountains where wind potential is very high, and are some $800-1000 \mathrm{~km}$ apart so that winds should not be highly correlated.

Wind speed measurements occurred at heights of $30 \mathrm{~m}$ and $50 \mathrm{~m}$ for the $\mathrm{BC}$ sites. We briefly discuss how wind speed measurements can be converted to power output. Wind power depends not only on wind speed but also on the height of the turbine hub, so measured wind velocity is adjusted using the following well-known relationship:

$$
V_{\text {hub }}=V_{\text {data }} \times\left(\frac{H_{\text {hub }}}{H_{\text {data }}}\right)^{\alpha},
$$

where $V_{h u b}$ is the wind velocity $(\mathrm{m} / \mathrm{s})$ at the turbine hub height, $V_{\text {data }}$ is the wind velocity $(\mathrm{m} / \mathrm{s})$ at the height it was measured, $H_{h u b}$ is the height of the wind turbine hub (m), $H_{\text {data }}$ is the height (m) at which the data was measured, and $\alpha$ is the site shear component that depends on the type of ground surface on which the wind turbine is built. We derive wind power output using power curves for wind turbine products from ENERCON GmbH (2007), assuming a 2.3 MW, Enercon E-70 wind turbine with hub height of $95 \mathrm{~m}$ and $71 \mathrm{~m}$ rotator diameter, and $\alpha=0.15$ in (1).

The artificially created hourly wind power data for north-eastern BC and the actual wind power output data for southern Alberta are each adjusted to a single2.3 MW turbine basis. The wind power information is summarized in Table 1. Data from each of the four northern wind sites are for a single turbine, so the combined data are divided by four. For sites in southern Alberta, hourly wind power outputs are divided by the total capacity (264 MW) of the seven wind farms in the analysis and multiplied by 2.3 . Using hourly data for one year, the simple coefficient of correlation between the individual northern and southern sites varies between -0.078 and -0.011 , implying little negative or no correlation. The correlation between individual northern sites varies between 0.435 and 0.847 , while it varies between 0.780 and 0.833 for individual southern sites, implying positive correlations within regions but not across regions. Nonetheless, the data indicate that there are 18 hours when no wind power is available, despite the negligible correlation between northern and southern sites; ${ }^{6}$ the maximum (standardized) wind power output for any given hour is $2.086 \mathrm{MW}$.

For illustrative purposes and reinforce a point made by Oswald et al. (2008), we consider a situation where some wind power is always available (although some of our key conclusions do not depend on the precise wind output series that is chosen). Thus, we added a fifth wind source based on a wind measurement site on Pulteney

\footnotetext{
${ }^{5}$ This is done so that a generating type can be represented by a single plant and for convenience to keep values small. However, it makes no difference to the analysis.

${ }^{6}$ Counting from the first hour in January, the hours with zero wind power output are 1691, 1692, 2299, $2336,2338,3176,3823-3826,4835,6445-6450$, and 7514.
} 
Table 1 Wind Penetration based on Western Canada wind sites

\begin{tabular}{lccc}
\hline Site & $\begin{array}{l}\text { Capacity } \\
(\mathrm{MW})\end{array}$ & $\begin{array}{l}\text { Production } \\
(\mathrm{GWh})\end{array}$ & $\begin{array}{l}\text { Capacity factor } \\
(\%)\end{array}$ \\
\hline Sites in southern Alberta currently in operation & & 28.7 \\
Castle River \#1 & 40 & 350.440 & 7.4 \\
Cowley Ridge & 38 & 332.918 & 27.4 \\
Kettles Hill & 9 & 78.849 & 34.4 \\
McBride Lake & 75 & 657.075 & 34.9 \\
Summerview & 68.4 & 599.252 & 36.6 \\
Suncor Magrath & 30 & 262.830 & 18.8 \\
Taylor Wind Farm & 3.6 & 31.540 & \\
Hypothetical sites in north-eastern & British Columbia ${ }^{\mathrm{a}}$ & & 21.1 \\
Aasen & 2.3 & 4.250 & 16.8 \\
Bessborough & 2.3 & 3.387 & 17.9 \\
Erbe & 2.3 & 3.603 & 35.0 \\
Bear Mountain & 2.3 & 7.044 & \\
\hline
\end{tabular}

Notes:

${ }^{a}$ Values are based on wind data for these sites, converted to power output for a single $2.3 \mathrm{MW}$ turbine as described in the text

Source: http://web.uvic.ca/ kooten/documents/LSRS2009WindData.xls

Point on the north end of Vancouver Island, British Columbia (see Prescott et al. 2007). This site is some 850-900 km from the nearest site east of the Rockies. We calculated the wind power output for this wind site assuming an Enercon E-70 turbine, and combined the resulting power output with that calculated for the four sites in north-eastern BC. Again we standardized the output to the single 2.3 MW capacity turbine by dividing the resulting wind power output by five (as we now have data from five sites). Again we find hours when there is absolutely no wind power output, although only four hours in this case. ${ }^{7}$ This illustrates a major problem: Given the diversity of locations and rather large distances between sites in western Canada, it is unlikely that any system that relies on wind power is going to be able to avoid times of zero wind power output. ${ }^{8}$ It is clear, therefore, that wind farms cannot be used to provide base-load power.

In order to have wind power available every hour, we need to add to our data the average wind power of the five BC sites, shifted forward by 24 hours. In this case, the minimum wind power output for any given hour is $0.005 \mathrm{MW}$ while the maximum is $1.779 \mathrm{MW}$ compared to $1.971 \mathrm{MW}$ before adjustments. However, given that the instantaneous capacity factor associated with minimum power level is only $0.2 \%$, it

\footnotetext{
${ }^{7}$ Hours 3823-3826 are without wind power output.

${ }^{8}$ This is similar to a problem discussed by Oswald et al. (2008): Weather systems affect very large geographical regions. It is possible for winds to be weak everywhere at the same time, even if monitoring sites are located a thousand or more $\mathrm{km}$ apart and separated by one or more mountain ranges.
} 
would be difficult to construct enough turbines in our closed system to permit wind to take on the role of a base-load plant.

\subsection{Load duration and system reserves}

A load duration curve is determined by sorting the system load (demand) in each hour from highest to lowest. The minimum or base load is generally met by a baseload power plant such as a coal or nuclear thermal generating facility. In our example, plotted in Fig. 1, the base load is $878 \mathrm{MW}$ compared to a peak load of $2500 \mathrm{MW}$. Load following facilities may consist of base-load plants, although combined-cycle gas turbine (CCGT) plants and hydroelectric are more optimal load-following facilities. These would cover load somewhere between the base load of $878 \mathrm{MW}$ and about $1400 \mathrm{MW}$ - that is, about 550-650 MW of load-following capacity is required. The remaining capacity needs to respond much more quickly as it must meet peak power demands that occur at certain times of the day and year. Open-cycle gas plants and hydropower stations are ideal peak load facilities.

A net load is constructed by subtracting, in each hour, wind output from demand (e.g., see Kennedy 2005). In Fig. 1, we created net load duration curves for wind penetration rates of $10 \%$ and $30 \%$, where wind penetration is defined as the ratio of installed wind capacity to peak load. ${ }^{9}$ The net load has to be met by conventional generators. Notice that the base load falls from $878 \mathrm{MW}$ to $751 \mathrm{MW}$, or by $14.5 \%$, for a wind penetration rate of $10 \%$, but to $389 \mathrm{MW}$, or by $55.7 \%$, for wind penetration of $30 \%$ ( $41.2 \%$ reduction compared to the $10 \%$ penetration base load). As the extent

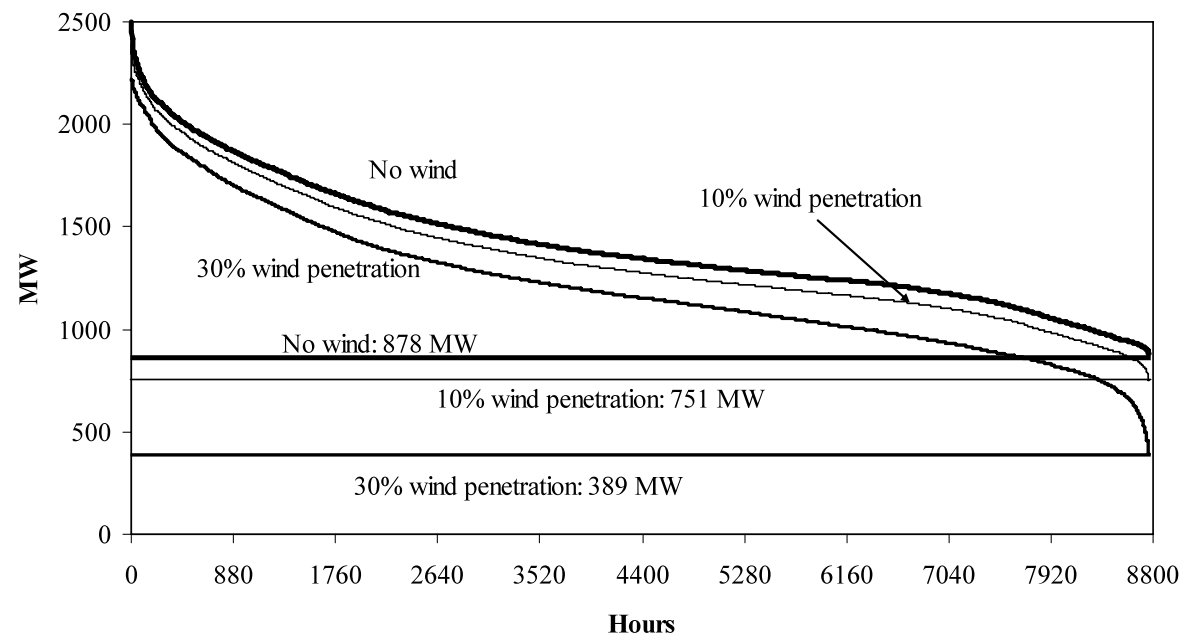

Fig. 1 Load duration curves and base loads with no wind, and $10 \%$ and $30 \%$ wind penetrations

\footnotetext{
${ }^{9}$ To obtain the requisite wind output, we simply multiply by the required number of turbines (plus fractions of turbines) to reach $250 \mathrm{MW}$ (10\% penetration) or $750 \mathrm{MW}(30 \%)$ wind capacity. A crucial assumption is that turbines do not interfere with each other, which is unlikely (see Rooijmans 2004). Also, the hours on the abscissa do not correspond one-for-one with those of the without-wind load duration curve.
} 


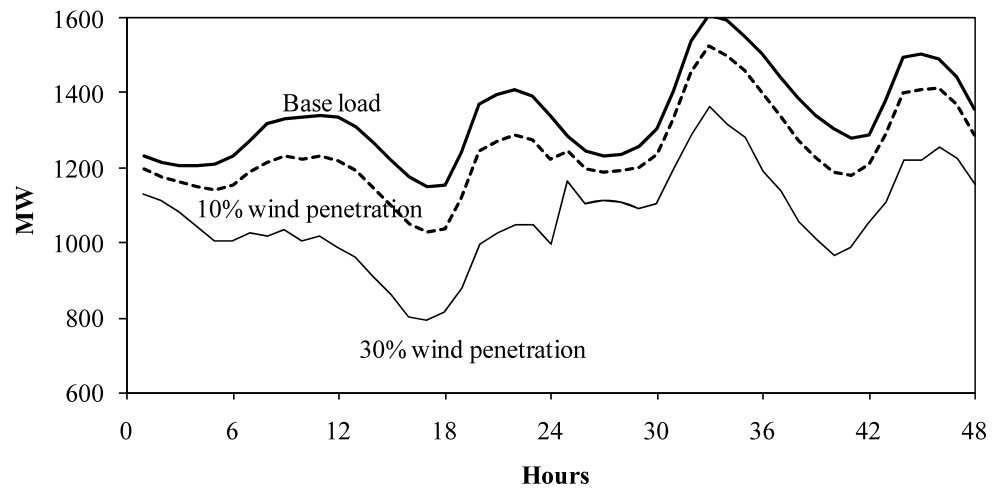

Fig. 2 Load to be met by traditional generators for first two days (48 hours) in January

of wind penetration rises, the costs of operating the system increase for at least two reasons. First, the net load duration curve is drawn as if wind power output is known with certainty, but wind output is highly variable, much more so than the variability in supply from traditional generation sources (due to planned and unplanned outages). Greater system balancing reserves are required with wind than without wind. Second, as wind penetrates the system, less of the system load is met by base-load power plants (unless the system operator curtails wind output). There is too much base-load capacity and insufficient peak-load capacity. This will increase the average systemwide power generation costs. Yet, as demonstrated above, wind is too unreliable to serve base-load needs, so it is not possible to eliminate traditional base-load capacity.

The introduction of wind power into an electrical grid increases the variability of the load to be met by traditional generating sources, making it harder for extant generators to follow the load by ramping up and down. This is shown in Fig. 2 where the ERCOT load with no wind is plotted (dark line) for the first two days in January. Also plotted are the hourly loads that need to be met when wind power enters the grid under $10 \%$ and $30 \%$ levels of penetration. Even though Fig. 2 only covers 48 hours, it is clear that the demand after non-dispatchable wind power has been subtracted has greater variability than the non-wind load, although the adjusted series still track the morning (6 am through noon) and evening (6 pm to $11 \mathrm{pm})$ peaks quite well. Clearly, and as evident in the figure, a $10 \%$ penetration level does not affect net load to the same extent as $30 \%$ penetration, although, if a longer profile were chosen, the volatility would be even sharper for both penetration levels. The effect that the variability in net load has on system costs and $\mathrm{CO}_{2}$ emissions is considered using a simple grid management model (Prescott et al. 2007; Prescott and van Kooten 2009).

The costs and benefits of introducing wind power into an electrical grid depend greatly on the characteristics of the electrical operating system, including the pattern of demand and importantly the extant generating mix (including tie-ins to other grids). To illustrate this, we construct an isolated grid model that employs the load and wind data underlying Figs. 1 and 2. We consider three alternative generating mixes - one that has a large degree of reliance on hydropower $(\mathrm{HH})$, a more typical mix (TT) and a mix that relies mainly on fossil fuels (FF). These are indicated in Table 2 and roughly correspond to the generation mixes of Canada, the United States 
Table 2 Generating mixes normalized to $2500 \mathrm{MW}$ capacity, three regions

\begin{tabular}{lccc}
\hline Technology & High Hydro (HH) & Typical (TT) & Fossil Fuel (FF) \\
\hline Hydroelectric & 1500 & 210 & 250 \\
Nuclear & 300 & 500 & 0 \\
Pulverized coal & 450 & 1250 & 1250 \\
Combined-cycle natural gas (CCGT) & 150 & 450 & 850 \\
Open-cycle NG (peak plant) & 100 & 90 & 150 \\
Total & $\mathbf{2 5 0 0}$ & $\mathbf{2 5 0 0}$ & $\mathbf{2 5 0 0}$ \\
\hline
\end{tabular}

Table 3 Cost data for generating technologies

\begin{tabular}{lclll}
\hline Technology & $\begin{array}{l}\text { Fuel Cost } \\
{[\$ / \mathrm{MWh}]^{\mathrm{a}}}\end{array}$ & $\begin{array}{l}\text { Variable O\&M } \\
{[\$ / \mathrm{MWh}]^{\mathrm{a}}}\end{array}$ & $\begin{array}{l}\text { Construction Cost } \\
{\left[\$ 10^{6} / \mathrm{MW}\right]^{\mathrm{b}}}\end{array}$ & $\begin{array}{l}\text { Emissions } \\
{\left[\mathrm{kg} \mathrm{CO} \text { per MWh }^{\mathrm{c}}\right.}\end{array}$ \\
\hline Hydroelectric & 1.13 & 0.02 & 1.550 & $0.009(0.0284)$ \\
Nuclear & 6.20 & 0.07 & 1.700 & $0.012(0.0147)$ \\
Pulverized coal & 13.70 & 0.70 & 1.100 & $0.980(1.1340)$ \\
Combined-cycle natural gas & 37.00 & 5.00 & 0.550 & $0.450(0.0496)$ \\
(CCGT) & & & & $0.650(0.0496)$ \\
Open-cycle NG (peak plant) & 41.00 & 4.50 & 0.460 & $0.015(0.0200)$ \\
Wind & 0 & 0.17 & 1.300 & \\
\hline
\end{tabular}

Notes:

${ }^{a}$ Source: Natural Resources Canada (2005)

${ }^{\mathrm{b}}$ Source: IEA (2005). These are 'overnight construction costs'- the costs of material, equipment and labor. The time required to build a plant is ignored, as are interest costs, risks (e.g., cost overruns), the useful life of generating facilities, cost of land, et cetera

${ }^{\mathrm{c}}$ Source: Summarized from Gagnon et al. (2002), Domenici et al. (2004) and Lightbucket (2008). Natural Resource Canada data are provided in parentheses

and Alberta. Fuel costs, variable operating and maintenance (O\&M) costs, and fixed investment costs by generating type are provided in Table 3. Also included in Table 3 are $\mathrm{CO}_{2}$ emissions per MWh by generating type, although such estimates vary greatly according to the source of fuel, age and type of the technology employed, capacity at which power plants operate, and whether they are based on a life-cycle analysis of power plant operations.

\subsection{Grid management model}

The grid management model can be represented mathematically as a constrained optimization (mathematical programming) problem as follows:

$$
\underset{Q_{t, i}}{\operatorname{Minimize}} T C=\underset{Q_{t, i}}{\operatorname{Minimize}} \sum_{t=1}^{24 \times d}\left[\sum_{i}\left(O M_{i}+b_{i}\right) Q_{t i}\right],
$$


where $T C$ is total cost $(\$) ; i$ refers to the generation source (viz., natural gas, coal, nuclear, wind, hydro); $d$ is the number of days (365 in our model); $t$ is the number of hours (8760); $Q_{t i}$ is the amount of electricity produced by generator $i$ in hour $t$ $(\mathrm{MW}) ; O M_{i}$ is operating and maintenance cost of generator $i(\$ / \mathrm{MWh})$; and $b_{i}$ is the variable fuel cost of producing electricity using generator $i(\$ / \mathrm{MWh})$, which is assumed constant for all levels of output. ${ }^{10}$ In addition, we define $D_{t}$ to be the demand or load that has to be met in hour $t$ (MW); $C_{i}$ is the capacity of generating source $i$ (MW); and $T_{i}$ is the amount of time it takes to ramp up production from plant $i$.

Objective function (2) is optimized subject to the following constraints:

Demand is met in every period (hour):

$$
\sum_{i} Q_{t, i}+\sum_{r} Q_{t, r} \geq D_{t}, \quad \forall t=1, \ldots, 24 \times d,
$$

Ramping-up constraint: $\quad Q_{t, i}-Q_{(t-1), i} \leq \frac{C_{i}}{T_{i}}, \quad \forall i$,

Ramping-down constraint: $\quad Q_{t, i}-Q_{(t-1), i} \geq-\frac{C_{i}}{T_{i}}, \quad \forall i$,

Capacity constraints: $\quad Q_{t, i} \leq C_{i}, \quad \forall i$,

Non-negativity: $\quad Q_{t, i} \geq 0$.

The model is linear and assumes rational expectations (there is no uncertainty even regarding wind availability), so there is also no need for a safety allowance. These assumptions are for simplicity only (although wind power output can be forecast with a relatively high degree of certainty) and do not in any way jeopardize the main points that we wish to make. Indeed, our conclusions would be all the more poignant if nonlinearities and uncertainty were added (see Maddaloni et al. 2008). We do however add two further constraints: thermal nuclear and coal-fired power plants must be kept running at $50 \%$ or more of their capacity to avoid shutting down base plants.

The cost functions in objective (2) are fuel and variable O\&M (constant marginal) costs found in Table 3; these represent a cost ranking of the five traditional generating facilities (open-cycle or peak gas $>$ CCGT gas $>$ coal $>$ nuclear $>$ hydroelectric). Then the ramping constraints are meant to represent a ranking of how fast a power plant adjusts its production. From the fastest to the slowest, the ranking used in this model is hydroelectric $=$ peak gas $>$ CCGT gas $>$ coal $>$ nuclear. ${ }^{11}$ The model is solved for 8760 hours representing a full year. Three scenarios are designed based on different wind energy penetration levels: a base case, a low (10\% penetration) wind scenario, and a high ( $30 \%$ penetration) wind scenario. The base case assumes that wind energy is not currently used to generate power with demand satisfied by the

\footnotetext{
${ }^{10} \mathrm{~A}$ carbon tax can be included by adding the following term to objective (2): $\tau \sum_{t=1}^{24 \times d}\left[\sum_{k} \varphi_{k} Q_{t, k}\right]$, where $\tau$ is a carbon tax ( $\$$ per $\mathrm{tCO}_{2}$ ) and $\varphi_{k}$ is the amount of $\mathrm{CO}_{2}$ required to produce a MWh of electricity from generation source $k$.

${ }^{11}$ Values of $T_{i}$ in constraints (4) and (5) are 1 hour (or less) for gas and hydro, 4 hours for coal to ramp up and 3 to ramp down, and 12 hours for nuclear plants to ramp up and 6 hours down.
} 
existing generating assets, depending on the generation mix that is modeled $(\mathrm{HH}, \mathrm{TT}$ or FF).

\section{Modeling results}

The purpose of the simulation is to indicate potential problems with attempts to integrate wind power into existing networks, and the ease with which this can be done is related to the generation mix. Although our model employs constant marginal generation costs (that vary only with generation type) and simple capacity limits and ramping constraints, the conclusions derived from the simulation results support those of other researchers (DeCarolis and Keith 2006; ESB 2004; Hirst and Hild 2004; Lund 2005; Nordel's Grid Group 2000; Prescott et al. 2007; Prescott and van Kooten 2009). These are discussed below.

The main electricity output and $\mathrm{CO}_{2}$ emission results are provided in Table 4 . Despite assuming perfect foresight regarding wind availability, generators cannot adapt quickly enough to prevent a rise in unnecessary generation. This is not true in the $\mathrm{HH}$ mix as hydroelectric output is able to adjust instantaneously to changes in wind, as indicated in Fig. 3(a). Nonetheless, the additional (unnecessary) electricity produced in the TT and FF mixes is modest (at most $1.1 \%$ above the no-wind scenario for the TT mix). Not surprisingly, the reduction in $\mathrm{CO}_{2}$ emissions is also relatively small, and largest for the fossil fuel mix. For 30\% wind penetration, the largest reduction in emissions amounts to only $14.5 \%$ of no-wind emissions, while emissions are reduced by only $1.3 \%$ and $8.1 \%$ for the respective $\mathrm{HH}$ and TT mixes. Clearly, the degree to which wind power is able to reduce an economy's $\mathrm{CO}_{2}$ emissions depends on the amount of hydroelectric and nuclear generating capacities there are in the generating mix. If wind displaces non- $\mathrm{CO}_{2}$ emitting hydro and nuclear power, the fewer will be the emission reduction benefits.

We assume that the construction cost of a wind power facility reported in Table 3 (\$1300 per $\mathrm{kW}$ ) was annualized using a 10\% discount rate and expected duration of 25 years. This constitutes the annual cost of adding wind power to a generating mix. The non-wind power generation costs and total costs (including construction costs for wind) are provided in Table 5, as are costs on a per $\mathrm{MWh}$ basis and $\mathrm{CO}_{2}$ emissions. The costs of reducing $\mathrm{CO}_{2}$ emissions are determined from this information and are provided in Table 6. Notice that system generation costs increase the most for the $\mathrm{HH}$ mix and least for the FF mix. Likewise, the costs of reducing $\mathrm{CO}_{2}$ emissions are highest for the $\mathrm{HH}$ mix and lowest for the FF mix, with the latter nearly competitive with other means of reducing $\mathrm{CO}_{2}$ emissions. The main conclusion is that investments in wind energy cannot be justified if $\mathrm{CO}_{2}$ offset permits can be purchased in carbon markets for $\$ 40 / \mathrm{tCO}_{2}$ or less, as has been the case in the European Trading System. In that case, wind energy should only be considered if there is also a desire to reduce dependence on fossil fuels for reasons not related to climate change, such as energy security. This conclusion might change for an FF-type mix if prices of coal rise or if one were to construct an electrical grid from the ground up, choosing the optimal configuration of generating plants_an option that might face some isolated and/or developing regions. 
Table 4 Electricity output and $\mathrm{CO}_{2}$ emissions by generating source for different generating mixes, and $0 \%, 10 \%$ and $30 \%$ levels of wind penetration

\begin{tabular}{|c|c|c|c|c|c|c|}
\hline \multirow{3}{*}{$\begin{array}{l}\text { Scenarios \& } \\
\text { Generating } \\
\text { Facility }\end{array}$} & \multicolumn{6}{|c|}{ Generating Mix } \\
\hline & \multicolumn{2}{|c|}{ High Hydro (HH) } & \multicolumn{2}{|c|}{ Typical (TT) } & \multicolumn{2}{|c|}{ Fossil Fuel (FF) } \\
\hline & $\begin{array}{l}\text { Output } \\
(\mathrm{GWh})\end{array}$ & $\begin{array}{l}\text { Emissions } \\
\left(\mathrm{tCO}_{2}\right)\end{array}$ & $\begin{array}{l}\text { Output } \\
\text { (GWh) }\end{array}$ & $\begin{array}{l}\text { Emissions } \\
\left(\mathrm{tCO}_{2}\right)\end{array}$ & $\begin{array}{l}\text { Output } \\
(\mathrm{GWh})\end{array}$ & $\begin{array}{l}\text { Emissions } \\
\left(\mathrm{tCO}_{2}\right)\end{array}$ \\
\hline \multicolumn{7}{|c|}{ No Wind (Base Case) } \\
\hline Hydro & 8940.9 & 80,468 & 1722.2 & 15,500 & 2189.7 & 19,708 \\
\hline Nuclear & 1412.9 & 16,955 & 3810.9 & 45,731 & na & na \\
\hline Coal & 2023.5 & $1,982,995$ & 6765.0 & $6,629,740$ & 9414.8 & $9,226,460$ \\
\hline CCGT & 5.5 & 2,493 & 85.1 & 38,282 & 777.7 & 349,949 \\
\hline Open gas & 0.6 & 397 & 0.4 & 281 & 1.3 & 816 \\
\hline Wind & na & na & na & na & na & na \\
\hline Total & $12,383.4$ & 2,083,309 & $12,383.7$ & $6,729,535$ & $12,383.4$ & $\mathbf{9 , 5 9 6 , 9 3 2}$ \\
\hline \multicolumn{7}{|c|}{$10 \%$ Wind Penetration } \\
\hline Hydro & 8391.6 & 75,525 & 1636.2 & 14,726 & 2182.5 & 19,642 \\
\hline Nuclear & 1389.2 & 16,671 & 3568.4 & 42,820 & na & na \\
\hline Coal & 2007.3 & $1,967,115$ & 6535.6 & $6,404,935$ & 8980.7 & $8,801,102$ \\
\hline CCGT & 1.9 & 877 & 57.8 & 26,025 & 626.7 & 282,017 \\
\hline Open gas & 0 & 0 & 0 & 0 & 0.2 & 116 \\
\hline Wind & 593.3 & 8,900 & 593.3 & 8,900 & 593.3 & 8,900 \\
\hline Total & $12,383.4$ & $2,069,088$ & $12,391.4$ & $6,497,406$ & $12,383.4$ & $9,111,777$ \\
\hline \multicolumn{7}{|c|}{$30 \%$ Wind Penetration } \\
\hline Hydro & 7259.8 & 65,339 & 1335.0 & 12,015 & 2064.8 & 18,584 \\
\hline Nuclear & 1356.4 & 16,277 & 3158.1 & 37,898 & na & na \\
\hline Coal & 1987.1 & $1,947,375$ & 6218.5 & $6,094,117$ & 8130.6 & $7,968,006$ \\
\hline CCGT & 0 & 0 & 26.4 & 11,897 & 417.1 & 187,690 \\
\hline Open gas & 0 & 0 & 0 & 0 & 0 & 0 \\
\hline Wind & 1780.0 & 26,700 & 1780.0 & 26,700 & 1780.0 & 26,700 \\
\hline Total & $12,383.4$ & $2,055,691$ & $12,518.1$ & $6,182,627$ & $12,392.6$ & $8,200,980$ \\
\hline
\end{tabular}

Note: na means not applicable

Consider also the impact of intermittent wind on the hour-to-hour operations of existing generators. In Fig. 4, we compare the impact on base-load nuclear and coal plants in going from no wind to $30 \%$ wind penetration. Despite their slow reaction times, nuclear and coal plants do exhibit increased variability in output as wind penetrates the grid (Fig. 4). CCGT plants (Fig. 5) are also base load but are relied upon to a lesser extent because the model will shift any burden carried by a gas plant towards the coal and nuclear facilities since these are required to operate above $50 \%$ of capacity and are cheaper to operate-the (constant) marginal cost of operating a gas plant is higher than that of a nuclear, coal or another facility (Table 3 ). The higher marginal cost explains why peak gas disappears entirely in all mixes when wind pen- 


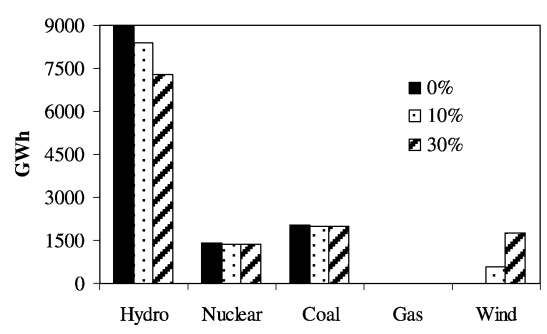

(a) High Hydro

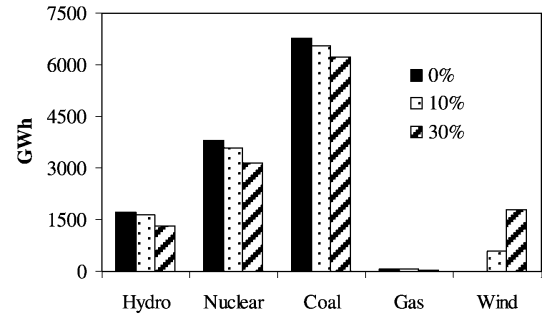

(b) Typical

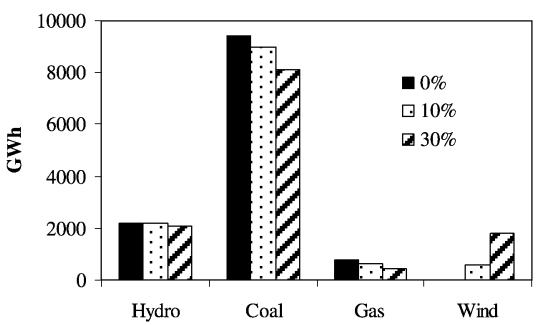

(c) Fossil Fuel

Fig. 3 Effect of wind penetration on output of existing generators, various generation mixes

Table 5 Generating mixes normalized to $2500 \mathrm{MW}$ capacity, electricity generated, costs and emissions

\begin{tabular}{|c|c|c|c|c|c|}
\hline Item & $\begin{array}{l}\text { Non-wind electricity } \\
\text { generated (GWh) }\end{array}$ & $\begin{array}{l}\text { Non-wind } \\
\text { cost (\$ mil) }\end{array}$ & $\begin{array}{l}\text { Total cost } \\
(\$ \text { mil })\end{array}$ & $\begin{array}{l}\text { Electricity } \\
\text { costs (\$/MWh) }\end{array}$ & $\begin{array}{l}\text { Emissions } \\
\left(\mathrm{Mt} \mathrm{CO}_{2}\right)\end{array}$ \\
\hline \multicolumn{6}{|c|}{ High hydro $(H H)$} \\
\hline $0 \%$ & 12,383 & 53.3292 & 53.3292 & 4.31 & 2.083 \\
\hline $10 \%$ & 11,790 & 52.0606 & 87.8653 & 7.45 & 2.069 \\
\hline $30 \%$ & 10,603 & 50.1096 & 157.5234 & 14.86 & 2.056 \\
\hline \multicolumn{6}{|c|}{ Typical (TT) } \\
\hline $0 \%$ & 12,383 & 142.8803 & 142.8803 & 11.54 & 6.730 \\
\hline $10 \%$ & 11,798 & 136.0054 & 171.8101 & 14.56 & 6.497 \\
\hline $30 \%$ & 10,738 & 126.1220 & 233.5359 & 21.75 & 6.183 \\
\hline \multicolumn{6}{|c|}{ Fossil Fuel (FF) } \\
\hline $0 \%$ & 12,383 & 195.0708 & 195.0708 & 15.75 & 9.597 \\
\hline $10 \%$ & 11,790 & 180.4431 & 216.2477 & 18.34 & 9.112 \\
\hline $30 \%$ & 10,613 & 156.0302 & 263.4440 & 24.82 & 8.201 \\
\hline
\end{tabular}

etration reaches $30 \%$, even though greater peaking capacity is generally needed as more intermittent wind enters the system (Prescott and van Kooten 2009).

Finally, we expand on our explanation of the above results. When non-dispatchable ('must-run') wind enters the grid, there will be a reduction in annual output from existing plants, but it will not be a one-for-one reduction-nuclear power output is very difficult to adjust, while coal can only be ramped slowly. Ideally, we would like coal output to be reduced, but this does not always happen, which is a key lesson of this re- 
Table 6 Costs of reducing $\mathrm{CO}_{2}$ emissions

\begin{tabular}{|c|c|c|c|c|}
\hline \multirow{2}{*}{$\begin{array}{l}\text { Generation mix/ } \\
\text { Wind penetration }\end{array}$} & \multicolumn{2}{|c|}{ Reducing emissions per $\mathrm{tCO}_{2}$} & \multicolumn{2}{|c|}{ Increase in per MWh costs } \\
\hline & $10 \%$ & $30 \%$ & $10 \%$ & $30 \%$ \\
\hline High hydro $(\mathrm{HH})$ & $\$ 2,467$ & $\$ 3,859$ & $73 \%$ & $245 \%$ \\
\hline Typical (TT) & $\$ 124$ & $\$ 166$ & $26 \%$ & $88 \%$ \\
\hline Fossil Fuel (FF) & $\$ 44$ & $\$ 49$ & $16 \%$ & $58 \%$ \\
\hline
\end{tabular}

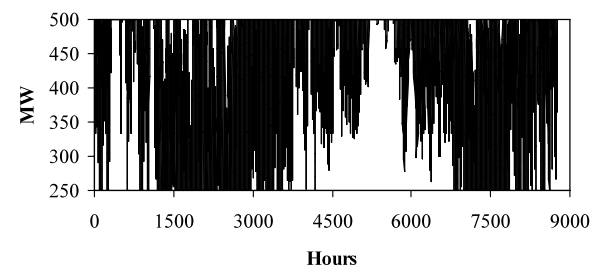

(a) No wind penetration

(Typical mix; nuclear plant)

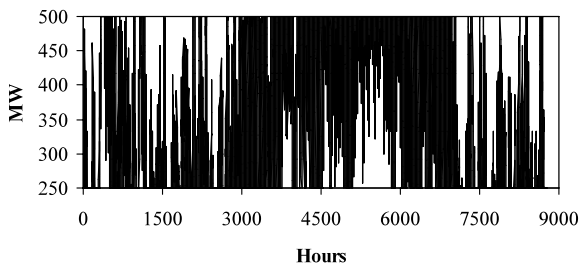

(b) $30 \%$ wind penetration

(Typical mix; nuclear plant)

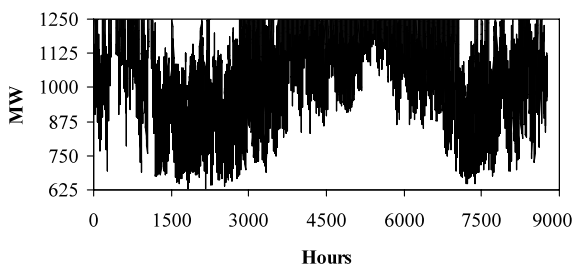

(c) No wind penetration

(Fossil fuel mix; coal plant)

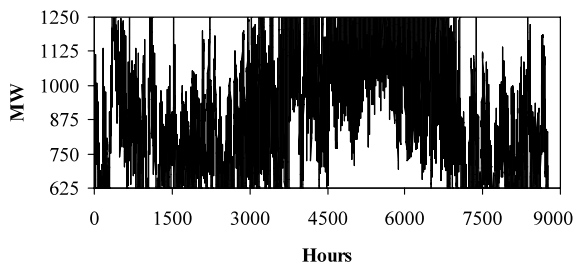

(d) $30 \%$ wind penetration

(Fossil fuel mix; coal plant)

Fig. 4 Hourly adjustment by base-load nuclear power plant for typical generating mix (left) and coal power plant for fossil fuel generating mix (right)

search. In the fossil fuel (FF) case (Figs. 3c, 4c, 4d and 5d), open-cycle gas and hydro are used to meet peak demand, but there is not enough generating capacity to enable the system to back completely away from reliance on these generating sourcesa certain amount of fast-response capacity is required in the system, particularly as wind enters. In the case of $30 \%$ wind penetration, peak gas can be eliminated because of its high costs, although hydro is still required for fast response. (Hydro capacity is about double that of peak gas in the TT and FF mixes.) Coal is the only alternative generating source in the FF case whose production can be reduced; coal output will ramp up and down in optimal fashion to track variability in wind generation, with fast-response hydro (or gas) covering coal generation in optimal fashion when it cannot track fluctuations in wind-adjusted load quickly enough. A similar thing happens in the typical generation mix.

In the high hydro (HH) grid (Fig. 3a), nuclear, coal and hydro are used to provide base-load power (as is the case in British Columbia, Quebec and Norway); hydropower can also serve fast-response needs and will, if possible, be used in place of open-cycle gas if it is available. It is optimal in this case to shut down peak and baseload gas entirely even in the absence of wind because of high operating costs and rely 


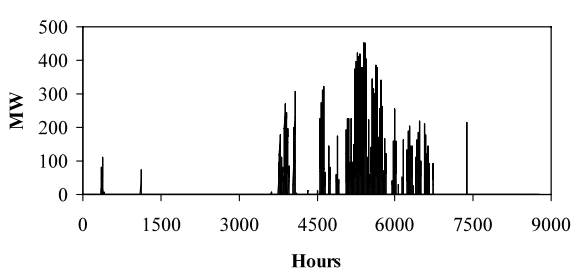

(a) No wind penetration (Typical mix)

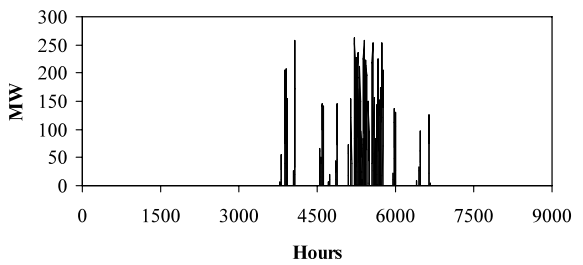

(b) 30\% wind penetration (Typical mix)

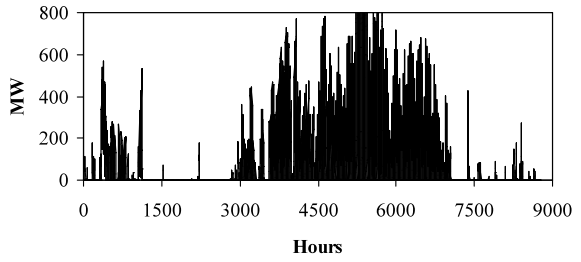

(c) No wind penetration (Fossil fuel mix)

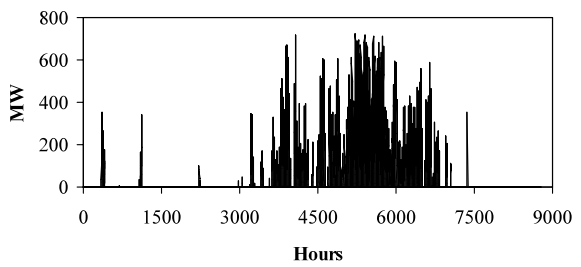

(d) 30\% wind penetration (Fossil fuel mix)

Fig. 5 Hourly adjustment by CCGT power plant for traditional and fossil fuel generating mixes

only on hydro for peaking needs (e.g., BC Hydro's one large gas plant is only used for a few hours per year and the government intends to shut it down). Given that there is only coal and nuclear base-load capacity left along with hydropower, it is primarily the hydro output that is reduced over the course of a year.

\section{Concluding observations}

The story regarding the integration of wind energy into existing electrical grids is a mixed one. There are undeniable benefits to wind power under certain conditions and in certain circumstances. Conditions depend to a large degree on the location of suitable wind sites, the availability of wind and economic factors. The best sites are those located on lands where wind turbines least interfere with other land uses, where noise and visual externalities are minimal, and where the effect on wildlife is small. To increase the reliability of wind power, sites should be scattered over a sufficiently large area so that they are not affected by the same weather patterns. Yet, as demonstrated by this research, this does not always prevent periods of low or zero wind, which makes wind totally unsuited for providing base-load electricity. Further, wind sites need to be connected to a transmission grid and, if such a grid does not exist in close proximity, the costs of deploying wind power become exceedingly large. Finally, the degree to which wind can benefit a jurisdiction, particularly in terms of reducing $\mathrm{CO}_{2}$ emissions, depends on the extant generating mix. Success is most guaranteed when wind power can displace large fossil fuel (primarily coal) generating capacity.

The presence of large-scale nuclear and hydro facilities militates against the use of wind to address climate change as wind power simply displaces hydroelectric and nuclear power, both of which have very low life-cycle greenhouse gas emissions. As our model indicates, the costs of reducing $\mathrm{CO}_{2}$ emissions are unacceptably large in 
such cases (and would theoretically be infinite if wind power displaces a carbon-free alternative one-for-one). A generating mix that might best be suited to greater deployment of wind farms is one that relies principally on fossil fuels yet has enough hydroelectric capacity to enable wind-generated power to be stored in hydro reservoirs. This is an issue that has not been explored here as it requires more detailed information than currently available.

While the analysis indicates that, compared to the case of no wind, the costs of integrating wind power are quite high, it is necessary to point out that the no-wind costs do not include returns to the fixed costs of existing power plants, but does include the annualized costs of establishing wind farms. The analysis focuses only on the marginal costs of existing facilities and these are assumed to be fixed. This was done because wind farms cannot possibly function as base-load facilities and the existing generation mix is unlikely to be changed in the near future; if anything, it is more likely that nuclear and/or coal plants that must be decommissioned for reasons of age will be replaced by similar facilities or base-load CCGT plants that can be built cheaply but are expensive to operate (because of high fuel costs). This has nothing to do with wind per se, but more with lack of planning, indecision and policies to reduce $\mathrm{CO}_{2}$ emissions (substituting gas for coal), or a combination of these factors.

Future research needs to focus on modeling the optimal replacement of existing power generating facilities, which was not done here. Future research also needs to determine methods of estimating economic as opposed to engineering supply (marginal cost) functions for various generating sources. Engineering costs do not adequately account for risk, integration of older and newer technologies, and other factors that are taken into account by more general economic cost functions.

What many analysts fail to consider in their enthusiasm for wind energy is the impact that wind has on existing base-load and peaking facilities. Results from our grid management model show that extant plants are negatively affected. This is likely the case because the extant mix of generation facilities into which wind power is introduced was nearly optimal to begin with, at least for the circumstances relevant to that jurisdiction (and at times when capacity was added to the system). Given that existing electrical grids cannot be changed overnight, it is probably prudent to introduce wind power into a grid at a pace that matches growth in demand and replacement of extant plants. Since electrical grids in many developing countries are not optimal, as seen by power shortages and frequent power outages, there may be greater benefits to the introduction of wind power in developing countries than developed ones.

In grids lacking hydro storage, solutions to wind intermittency have focused on other forms of storage (primarily compressed air) or use of fast-responding natural gas plants to cover periods of low or zero wind output (Greenblatt et al. 2007; Cavallo 1995). Storage is expensive and often unavailable, while wind variability itself undermines the incentive to invest in fast-response gas plant capacity. As our results in Table 4 indicate, when wind penetration increases, the need for fastresponding power generation also declines, perhaps to the point where such generation is driven to zero. Although this is an artifact of the assumed constant marginal costs used in the current model, there is insufficient information about the economic costs of various generation sources (as opposed to engineering costs of individual generators or plants) to settle the issue one way or the other. 
Finally, to alleviate grid stability problems and make the grid easier to manage when large amounts of wind power enter, wind power can be made dispatchable with wind operators required to reduce output (by 'feathering' wind turbines or simply stopping blades from rotating) whenever the grid operator is unable to absorb extra electricity. (This was a pre-condition in Alberta before installed wind capacity was permitted to exceed $900 \mathrm{MW}$.) In this case, output from base-load plants is given precedence over wind generated power. However, this policy makes investments in wind farms less attractive, while environmentalists generally oppose policies that curtail wind generation as this is considered 'wasteful' of a renewable resource.

Open Access This article is distributed under the terms of the Creative Commons Attribution Noncommercial License which permits any noncommercial use, distribution, and reproduction in any medium, provided the original author(s) and source are credited.

\section{References}

Cavallo, A.J.: High-capacity factor wind energy systems. J. Sol. Energy Eng. 117, 137-143 (1995)

DeCarolis, J.F., Keith, D.W.: The economics of large-scale wind power in a carbon constrained world. Energy Policy 34(4), 395-410 (2006)

Domenici, P.V., Lyons, B.J., Stevn, J.J.: A Brighter Tomorrow: Fulfilling the Promise of Nuclear Energy. Roman \& Littlefield, Lanham (2004)

ENERCON: Enercon: Energy for the world. Enercon Gmbh. http://www.enercon.de/en/_home.htm (2007). Accessed 20 June 2008

ESB: Impact of wind power generation in Ireland on the operation of conventional plant and the economic implications. February. ESB National Grid, Dublin (2004)

Gagnon, L., Belanger, C., Yohji, U.: Life-cycle assessment of electricity generation options: The status of research in year 2001. Energy Policy 30, 1267-1278 (2002)

Greenblatt, J.B., Succar, S., Denkenberger, D.C., Williams, R.H., Socolow, R.H.: Baseload wind energy: modeling the competition between gas turbines and compressed air energy storage for supplemental generation. Energy Policy 35(3), 1474-1492 (2007)

Gross, R., Leach, M., Bauen, A.: Progress in renewable energy. Environ. Int. 29(1), 105-122 (2003)

Gross, R., Heptonstall, P., Anderson, D., Green, T., Leach, M., Skea, J.: The Costs and Impacts of Intermittency: An Assessment of the Evidence on the Costs and Impacts of Intermittent Generation on the British Electricity Network. Energy Research Centre, London (2006)

Gross, R., Heptonstall, P., Leach, M., Anderson, D., Green, T., Skea, J.: Renewables and the grid: Understanding intermittency. ICE Proc. Energy 160(1), 31-41 (2007)

Hirst, E., Hild, J.: Integrating Large Amounts of Wind Energy with a Small Electric-Power System. Excel Energy, Denver and Bellingham (2004)

IEA: Projected costs of generating electricity. 2005 update. Nuclear Energy Agency, IEA, OECD, Paris (2005)

Kennedy, S.: Wind power planning: Assessing long-term costs and benefits. Energy Policy 33(13), 16611575 (2005)

Lightbucket: Carbon emissions from electricity generation: JUST the numbers. wordpress.com. http://lightbucket.wordpress.com/2008/02/20/carbon-emissions-from-electricity-generation-just-thenumbers/ (2008). Accessed 10 July 2008

Love, M., Lawrence, P., Niet, T., McLean, G.: Utility-scale energy systems: Spatial and storage requirements. IESVic Working Paper, University of Victoria, Victoria (2003)

Lund, H.: Large-scale integration of wind power into different energy systems. Energy 30(13), 2402-2412 (2005)

Maddaloni, J.D., Rowe, A.M., van Kooten, G.C.: Network constrained wind integration on Vancouver Island. Energy Policy 36(2), 591-602 (2008)

Natural Resources Canada: Greenhouse gas and cost impacts of electric markets with regional hydrogen production. Report No. 2007. Government of Canada, Ottawa (2005) 
Nordel's Grid Group: Non-dispatchable production in the Nordel system. Report Presented at the Nordel's Annual Meeting, May (2000)

Oswald, J., Raine, M., Ashraf-Ball, H.: Will British weather provide reliable electricity? Energy Policy 36(8), 3202-3215 (2008)

Pitt, L., van Kooten, G.C., Love, M., Djihali, N.: Utility-scale wind power: Impacts of increased penetration. Paper No. IGEC-097. In: Proceedings of the International Green Energy Conference, Waterloo (2005)

Piwko, R., Osborn, D., Gramlich, R., Jordan, G., Hawkins, D., Porter, K.: Wind energy delivery issues. IEEE Power Energy Mag. 3, 47-56 (2005)

Prescott, R., van Kooten, G.C.: Economic costs of managing of an electricity grid with increasing wind power penetration. Clim. Policy 9(2), 155-168 (2009)

Prescott, R., van Kooten, G.C., Zhu, H.: Potential for wind energy meeting electricity needs on Vancouver Island. Energy Environ. 18(6), 723-746 (2007)

Rooijmans, P.: Impact of a large-scale offshore wind farm on meteorology: numerical simulations with a mesoscale circulation model. Masters Thesis, Utrecht University, The Netherlands (2004)

van Kooten, G.C., Timilsina, G.R.: Wind power development: Economics and policies. Policy Research Working Paper 4868. World Bank, Washington (2009) 